\title{
Adjuvant gemcitabine and concurrent radiation for patients with resected pancreatic cancer: a phase II study
}

\author{
AW Blackstock*,, F Mornex ${ }^{2}$, C Partensky², L Descos², LD Case', SA Melin', EA Levine', G Mishra', \\ SA Limentani ${ }^{3}$, LA Kachnic ${ }^{4}$ and JE Tepper ${ }^{5}$ \\ 'Department of Radiation Oncology, Wake Forest University School of Medicine, Medical Center Blvd, Winston-Salem, NC 27I 57, USA; ${ }^{2}$ Centre \\ Hospitalier Lyon Sud Radiation Oncology Department, Pierre Benite 693 I0, Lyon, France; ${ }^{3}$ Blumenthal Cancer Center, 1000 Blythe Blvd \#60 I, Charlotte, \\ NC 28203, USA; ${ }^{4}$ Boston University Medical Center, 88 East Newton St, EB II, Boston, MA 02 I I8, USA; ${ }^{5}$ University of North Carolina, Manning Drive, \\ Chapel Hill, NC 27599, USA
}

The safety and efficacy of gemcitabine and concurrent radiation to the upper abdomen followed by weekly gemcitabine in patients with resected pancreatic cancer was determined. Patients with resected adenocarcinoma of the pancreas were treated with intravenous gemcitabine administered twice-weekly $\left(40 \mathrm{mg} \mathrm{m}^{-2}\right)$ for 5 weeks concurrent with upper abdominal radiation (50.4 Gy in $5 \frac{1}{2}$ weeks). At the completion of the chemoradiation, patients without disease progression were given gemcitabine $\left(1000 \mathrm{mg} \mathrm{m}^{-2}\right)$ weekly for two cycles. Each cycle consisted of 3 weeks of treatment followed by I week without treatment. Forty-seven patients were entered, 46 of whom are included in this analysis. Characteristics: median age 6I years (range 35-79); 24 females (58\%); 73\% stage T3/T4; and 70\% lymph node positive. Grade III/IV gastrointestinal or haematologic toxicities were infrequent. The median survival was 18.3 months, while the median time to disease recurrence was 10.3 months. Twenty-four percent of patients were alive at 3 years. Only six of 34 patients with progression experienced local regional relapse as a component of the first site of failure. These results confirm the feasibility of delivering adjuvant concurrent gemcitabine and radiation to the upper abdomen. This strategy produced good local regional tumour control.

British Journal of Cancer (2006) 95, 260-265. doi:I 0.I038/sj.bjc.6603270 www.bjcancer.com

Published online 25 July 2006

(c) 2006 Cancer Research UK

Keywords: pancreatic; adjuvant; gemcitabine; chemoradiation

Cure with surgery alone for patients with operable pancreatic adenocarcinoma remains infrequent. A small randomised trial reported by the Gastrointestinal Study Group (GITSG) demonstrated an improvement in median and overall survival for patients treated with a surgical resection who were randomised to adjuvant 5 -fluorouracil-based chemoradiation ( $v s$ observation) (1987). The chemoradiation consisted of bolus 5-fluorouracil (5-FU) and split course radiation to a total dose of $40 \mathrm{~Gy}$. The median and 2-year survival for the surgery alone patients was 11 months and $18 \%$ vs 20 months and $43 \%$, respectively, for the patients receiving adjuvant therapy. The European Organization for the Research and Treatment of Cancer (EORTC) attempted to replicate the results of the GITSG trial but failed to confirm a statistical benefit, despite a 4.5-month improvement in median survival for patients receiving adjuvant chemoradiation (Klinkenbijl et al, 1999). In an update of the European Study for Pancreatic Cancer (ESPAC 1) trial, six cycles of adjuvant 5-FU chemotherapy given alone or following split-course 5-FU-based chemoradiation appeared to provide a survival benefit over surgery alone (Neoptolemos et al, 2004). While the results of the ESPAC trial leave in question the role of radiation therapy in this setting, the use of chemoradiation reflects an accepted standard in the United States.

*Correspondence: Dr AW Blackstock; E-mail: ablackst@wfubmc.edu Received 27 February 2006; revised 15 June 2006; accepted 15 June 2006; published online 25 July 2006
Gemcitabine is active as a single agent in the treatment of pancreatic cancer (Casper et al, 1994; Carmichael et al, 1996; Burris et al, 1997) with established radiation sensitising properties (Shewach and Lawrence, 1995, 1996; Lawrence et al, 1996, 1997, 1999; Joschko et al, 1997; Blackstock et al, 2001). While the vast majority of the reported phase I-III clinical trials have utilised gemcitabine as a single agent given weekly in a single dose, there are preclinical, pharmacologic and clinical data suggesting gemcitabine possesses equal, if not greater, cytotoxicity if given at a lower dose over a longer infusion time (Gandhi and Plunkett, 1990; Grunewald et al, 1991; Boven et al, 1993; Shewach et al, 1994).

Animal studies from the University of Michigan and MD Anderson Cancer Center suggest that maximum radiation sensitisation with gemcitabine is achieved with a lower dose administered twice-weekly (Mason et al, 1999; Fields et al, 2000). Fields et al treated squamous cell carcinoma VII xenografts with ionising radiation combined with isotoxic drug/radiation regimens (gemcitabine $800 \mathrm{mg} \mathrm{kg}^{-1}$ once weekly or $100 \mathrm{mg} \mathrm{kg}^{-1}$ twiceweekly). At 28 days post-treatment, tumours treated with twiceweekly gemcitabine and radiation were significantly smaller than tumours treated with the once weekly schedule $(P<0.03)$. Related supporting clinical data come from Eisbruch et al (2001). Twentynine patients with unresectable head and neck cancer received a course of radiation concurrent with weekly infusions of low-dose gemcitabine. Tumour biopsies were obtained after the first gemcitabine infusion (before radiation started), and the intracellular 
concentrations of dFdCTP, the active metabolite of gemcitabine, were determined. Tumour $\mathrm{dFdCTP}$ levels and response rates were similar at all dose levels $\left(50-300 \mathrm{mg} \mathrm{m}^{-2}\right)$, demonstrating that significant tumour and normal tissue radiosensitisation can be achieved with 'low-dose' gemcitabine strategies.

Several phase I/II trials combining upper abdominal radiation and lower dose $\left(40-90 \mathrm{mg} \mathrm{m}^{-2}\right)$ twice-weekly gemcitabine have been reported, with each suggesting that this combination is safe and active (Blackstock et al, 1999; Pipas et al, 2001; Yavuz et al, 2001; Martenson et al, 2003). In a preoperative trial in pancreatic cancer from Joensuu et al (2004), the investigators observed a median survival of 25 months for patients taken to resection after receiving preoperative twice-weekly gemcitabine and radiation. While survival in the Cancer and Leukemia Group B (CALGB) trial of twice-weekly gemcitabine and radiation for locally advanced unresectable patients was only comparable to that expected with 5-FU-based chemoradiation, the regimen possessed moderate but acceptable toxicity and local control appeared improved (Blackstock et al, 2004).

This study was initiated to evaluate the combination of adjuvant radiation with concurrent twice-weekly gemcitabine followed by gemcitabine for patients with resected pancreatic cancer.

\section{PATIENTS AND METHODS}

\section{Patient population}

Patient's age $\geqslant 18$ years with nonmetastatic surgically resected adenocarcinoma of the pancreas by pancreaticoduodenectomy (Whipple procedure or total pancreatectomy) were eligible. While patients with resected nodal disease were eligible, patients with focally positive (microscopically) margins (tumour at the margin) or patient's $\geqslant 8$ weeks from surgery were ineligible. Inclusion criteria were the following: Eastern Cooperative Oncology Group performance status (PS) 0-2; adequate bone marrow - ANC (absolute neutrophil count) $\geqslant 1500$ cells $\mathrm{mm}^{-3}$, platelet count $\geqslant 100000$ cells $\mathrm{mm}^{-3}$, and haemoglobin $\geqslant 10 \mathrm{~g} \mathrm{dl}^{-1}$; kidney function (serum creatinine $<2.0 \mathrm{mg} \mathrm{dl}^{-1}$ ) and liver function (serum total bilirubin $<2 \mathrm{mg} \mathrm{dl}^{-1}$ ). Only patients able to maintain adequate oral nutrition and document a stable weight (no more than $5 \mathrm{lbs}$ weight loss) for at least 2 weeks prior to enrollment were eligible. Patients with prior malignancy were ineligible for the study with the exception of those who had nonmelanoma skin cancer, in situ cancer of the cervix, or other cancer for which the patient had been disease free for $\geqslant 5$ years.

All patients provided written informed consent according to federal and institutional guidelines. Institutional review board approvals were obtained at all participating sites.

\section{Treatment and evaluation}

A complete course of therapy was defined as a total of 18 weeks or three cycles. Cycle 1 (weeks 1-6) incorporated the chemoradiation portion of the trial. Gemcitabine was delivered intravenously at a dose of $40 \mathrm{mg} \mathrm{m}^{-2}$ over $30 \mathrm{~min}$, twice-weekly on either Monday and Thursday or Tuesday and Friday 30 min prior to the radiation therapy. During the concurrent chemoradiation, the gemcitabine was held for 1 week if the ANC was $<1500 \mu 1^{-1}$ or the platelets were $<100000 \mathrm{~mm}^{-3}$ at the scheduled Monday dosing (the radiation continued). If the ANC or platelets had not recovered after the 1 week break, the gemcitabine and radiation were held until the ANC or platelets recovered and then restarted (no gemcitabine dose reductions). Gemcitabine doses held due to toxicity were not made up. Preoperative CT scans of the abdomen and surgical clips placed at the time of surgery were used to delineate treatment volumes. An initial $45 \mathrm{~Gy}$ was delivered to the tumour bed and peripancreatic nodal regions plus a $1.0-2.0 \mathrm{~cm}$ margin. The celiac axis was treated at the discretion of the radiation oncologist. The boost volume included the original tumour bed volume with a $2.0 \mathrm{~cm}$ margin. This volume received an additional $5.4 \mathrm{~Gy}$. The specific design and configuration of the fields were individualised based upon the volume and location of the disease. Four field beam arrangements and $10-15 \mathrm{mV}$ photon energies were required. In general, a four-field approach utilised anterior-posterior and left and right lateral beams. The spinal cord dose was limited to $45 \mathrm{~Gy}$. In order to decrease hepatic irradiation, the anterior-posterior (AP/PA) fields were generally weighted more heavily than the laterals.

During cycles 2-3, gemcitabine was administered intravenously at a dose of $1000 \mathrm{mg} \mathrm{m}^{-2}$ over $30 \mathrm{~min}$ weekly for 3 weeks followed by 1 week of rest $\times 2$ cycles. Within a cycle, if the ANC was between 500 and $999 \mu \mathrm{l}^{-1}$ or the platelet count was between 50000 and $99999 \mathrm{~mm}^{-3}$ on the day of treatment, the dose of gemcitabine was reduced by $25 \%$. The dose was held for an ANC less than $500 \mu \mathrm{l}^{-1}$ or a platelet count less than $50000 \mathrm{~mm}^{-3}$. Patients with nonhaematologic toxicities grades $0-2$ (and grade 3 nausea/ vomiting) received full-dose gemcitabine. For grade 3 nonhaematologic toxicities other than nausea/vomiting, patients received either $75 \%$ of the gemcitabine dose or no treatment at the discretion of the treating physician. The gemcitabine dose was held for grade 4 nonhaematologic toxicities and missed doses were not made up.

Patients were evaluated for disease progression clinically and radiographically every 2 months the first year and then every 3 months. Weekly complete blood cell counts were required during treatment and the use of growth factors was discouraged. Disease progression was defined as the appearance of any new lesions on radiographic studies or in patients experiencing complications consistent with local-regional progression of disease, including new gastric outlet obstruction, duodenal obstruction, new bile duct obstruction, a decline in PS of at least one level, or the development of ascites not associated with gemcitabine therapy.

\section{Statistical considerations}

The statistical analysis was performed at the Wake Forest University Comprehensive Cancer Center. The principal outcome measure used to quantify treatment effect was the Kaplan-Meier estimated 1-year survival. A two-stage phase II design was planned to test the null hypothesis that 1-year survival was $\leqslant 35 \%$ vs the alternative hypothesis that 1 -year survival was $\geqslant 50 \%$ with type I and II errors of $10 \%$. The study was originally designed to accrue a maximum of 82 patients with an interim analysis after 53 patients. As the accrual was slower than expected, the study was closed with a sample size of 47 patients that provided an $78 \%$ power for testing the study hypothesis. The Kaplan-Meier method was also used to estimate the progression-free survival distribution. Overall survival was measured from the date of study entry until death due to any cause. Recurrence-free survival was measured from the date of study entry until disease progression or death from any cause. The log-rank test was used to assess differences in time-to-event distributions between patient subgroups.

Patient registration and data collection were managed by the Wake Forest University Statistical Center (US) and Centre Hospitalier Lyon Sud (France). Data quality was ensured by careful review of all data by the Wake Forest University Statistical Center, the Centre Hospitalier Lyon Sud staff and the study chairpersons.

\section{RESULTS}

\section{Patient characteristics}

Between June of 1999 and October of 2003, 47 patients with resected pancreatic cancer were entered onto this multicenter trial. 
This analysis incorporates data available from 46 patients, excluding one patient who was entered but was subsequently deemed ineligible (median follow-up 38.6 months). The pretreatment characteristics of the patients entered onto this trial are listed in Table 1. The median age was 61 years (range 35-79 years), all patients were resection margin negative and the median number of lymph nodes evaluated was 7 (range 1-27). The majority of patients $(>70 \%)$ were lymph node positive and had advanced T-stage disease.

\section{Toxicity}

Table 2 shows the grade 3 and 4 toxicities. Grade 3 and grade 4 haematologic toxicities, primarily neutropenia, occurred in 15 and $11 \%$ of patients, respectively. Grade 3 and 4 gastrointestinal toxicities, specifically nausea and vomiting, were uncommon, occurring in $13 \%$ and $0 \%$ of patients respectively. There was one death attributed to a gastrointestinal bleed that was scored as possibly treatment related. Forty-six percent of patients completed all 18 weeks of planned therapy while $74 \%$ of patients completed all planned chemoradiation and received $\geqslant 50 \%$ of the intended doses of maintenance chemotherapy.

\section{Survival and patterns of failure}

The median survival and progression-free survival for the entire patient cohort were $18.3(95 \% \mathrm{CI}=13.7,25.9)$ months and 10.3 $(95 \% \mathrm{CI}=9.0,13.2)$ months, respectively. Sixty-nine percent $(95 \%$ $\mathrm{CI}=0.55,0.83$ ) of patients were alive at 1 year and $24 \%$ were alive at 3 years (Figure 1). T-stage was prognostic; the time to

Table I Patient characteristics

\begin{tabular}{|c|c|c|}
\hline Characteristic & No. & (\%) \\
\hline Total & 46 & $(100)$ \\
\hline Age - median (range) & $61(35-79)$ & \\
\hline \multicolumn{3}{|l|}{ Country } \\
\hline France & 21 & (46) \\
\hline USA & 25 & (54) \\
\hline \multicolumn{3}{|l|}{ Performance status } \\
\hline ECOG 0 & 30 & $(65)$ \\
\hline ECOG I & 15 & (33) \\
\hline ECOG 2 & । & (2) \\
\hline \multicolumn{3}{|l|}{ Sex } \\
\hline Male & 22 & $(48)$ \\
\hline Female & 24 & (52) \\
\hline \multicolumn{3}{|l|}{ Ethnicity } \\
\hline Caucasian & 43 & (93) \\
\hline African-American & 3 & (7) \\
\hline \multicolumn{3}{|l|}{ Tumour size } \\
\hline$\geqslant 3.0 \mathrm{~cm}$ & 27 & (64) \\
\hline$<3.0 \mathrm{~cm}$ & 15 & (36) \\
\hline Unknown & 4 & $(-)$ \\
\hline \multicolumn{3}{|l|}{ Lymph node } \\
\hline Negative & 13 & (30) \\
\hline Positive & 30 & (70) \\
\hline Unknown & 3 & $(-)$ \\
\hline \multicolumn{3}{|l|}{ Tumour stage } \\
\hline $\mathrm{T} 1 / \mathrm{T} 2$ & 12 & (27) \\
\hline $\mathrm{T} 3 / \mathrm{T} 4$ & 32 & (73) \\
\hline Unknown & 2 & $(-)$ \\
\hline
\end{tabular}

recurrence for patients with $\mathrm{T} 1-\mathrm{T} 2$ disease was 16 months $v s 9.2$ months for patients with T3-T4 tumours $(P=0.05)$. Overall median survival trended towards statistical significance as it related to T-stage, 30.7 months for the $\mathrm{T} 1-\mathrm{T} 2$ patients $v s 14.6$ for patients with T3-T4 tumours $(P=0.06)$. Neither ethnicity nor gender was related to survival (Table 3 ); however, there were very few African-American patients in this study. While patients in the US experienced a slightly improved survival (nonstatistical), this likely relates to the overall more advanced T-stage and nodal stage disease found in patients enrolled in France.

At the time of this analysis, documented progression had occurred in 34 of the 46 patients. Three other patients died of their disease and were considered to have progressed. Distant progression represented the most frequent location of initial treatment failure (Table 4). Recurrence in the liver was a component of failure in 28 of 34 patients $(82 \%)$ while six patients $(18 \%)$ developed pulmonary metastasis. Ascites indicative of peritoneal carcinomatosis occurred in five of 34 (15\%). Local-regional recurrence was observed in six of 34 patients who progressed $(18 \%)$.

\section{DISCUSSION}

The vast majority of the reports attempting to combine upper abdominal radiation and gemcitabine have been in the setting of locally advanced pancreatic cancer. In several instances, the

Table 2 Grade III and IV toxicities experienced in 46 evaluable patients

\begin{tabular}{|c|c|c|c|c|}
\hline \multirow[b]{2}{*}{ Toxicity } & \multicolumn{2}{|c|}{ Grade 3} & \multicolumn{2}{|c|}{ Grade 4} \\
\hline & $n$ & (\%) & $n$ & (\%) \\
\hline \multicolumn{5}{|l|}{ Haematologic } \\
\hline Neutrophils/granulocytes & 7 & (15) & 5 & $(||)$ \\
\hline Anaemia & 8 & (17) & 2 & (4) \\
\hline Thrombocytopenia & 6 & (13) & 1 & (2) \\
\hline \multicolumn{5}{|l|}{ Constitutional } \\
\hline Fatigue (lethargy/malaise) & 10 & (22) & 0 & (0) \\
\hline Weight loss & । & (2) & 0 & (0) \\
\hline \multicolumn{5}{|l|}{ Gastrointestinal } \\
\hline Anorexia & I & (2) & I & (2) \\
\hline Nausea & 6 & (13) & 0 & (0) \\
\hline Dehydration & 0 & $(0)$ & 0 & (0) \\
\hline Vomiting & 2 & (4) & 0 & (0) \\
\hline
\end{tabular}

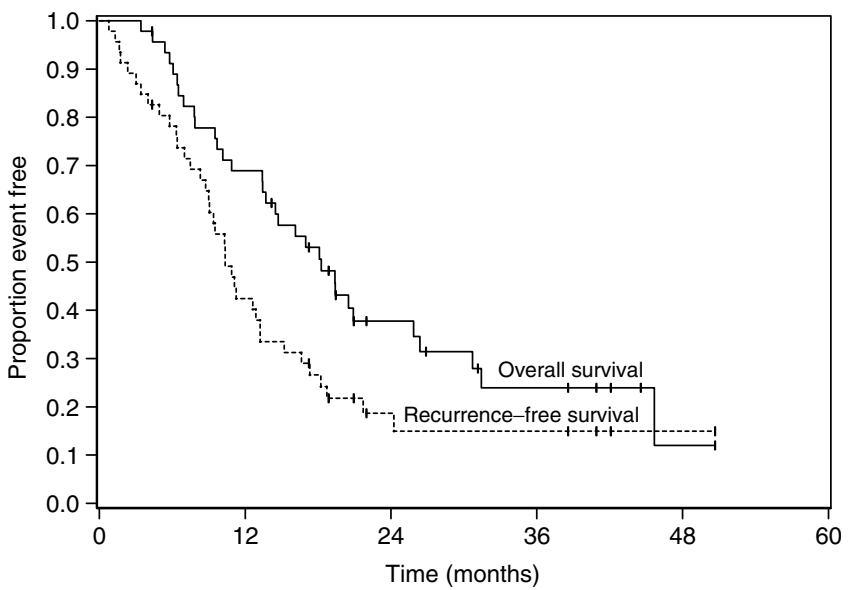

Figure I Overall and recurrence free survival. 
Table 3 Overall survival (in months) by demographic characteristics

\begin{tabular}{|c|c|c|c|c|}
\hline Characteristic & $n$ & Median & $95 \% \mathrm{Cl}$ & $P$-value \\
\hline Overall & 46 & 18.3 & $13.7,25.9$ & \\
\hline Age group & & & & 0.44 \\
\hline$<60$ & 22 & 20.5 & $\mid 4.5,31.4$ & \\
\hline$\geqslant 60$ & 24 & 14.7 & $9.5,25.9$ & \\
\hline Country & & & & 0.21 \\
\hline France & 21 & 17.0 & $7.8,25.9$ & \\
\hline USA & 25 & 19.4 & 13.7, NA & \\
\hline Gender & & & & 0.83 \\
\hline Female & 24 & 19.4 & $10.9,30.7$ & \\
\hline Male & 22 & 18.1 & $14.5,25.9$ & \\
\hline Ethnicity & & & & 0.10 \\
\hline African descent & 3 & 13.7 & $4.4,18.3$ & \\
\hline Non African descent & 43 & 19.4 & $13.4,26.4$ & \\
\hline Performance status & & & & 0.29 \\
\hline 0 & 30 & 18.3 & $13.4,25.9$ & \\
\hline $1-2$ & 16 & 16.1 & 10.2, NA & \\
\hline Tumour size & & & & 0.23 \\
\hline$<3 \mathrm{~cm}$ & 15 & 16.1 & $10.9,20.5$ & \\
\hline$\geqslant 3 \mathrm{~cm}$ & 27 & 19.4 & 13.7, 45.7 & \\
\hline Nodal status & & & & 0.15 \\
\hline Negative & 13 & 30.7 & 13.7. NA & \\
\hline Positive & 30 & 15.4 & $9.7,20.5$ & \\
\hline Stage & & & & 0.07 \\
\hline TI,2 & 12 & 30.7 & 18.3, NA & \\
\hline $\mathrm{T} 3,4$ & 32 & 14.6 & $10.2,20.9$ & \\
\hline
\end{tabular}

NA, not applicable

Table 4 Sites of first recurrence

\begin{tabular}{lcc}
\hline Organ site & $\begin{array}{c}\text { Number of } \\
\text { patients }\end{array}$ & $\begin{array}{c}\text { \% of patients with } \\
\text { documented progressions }\end{array}$ \\
\hline Liver & 28 & $(82)$ \\
Pancreas/regional nodes & 6 & $(18)$ \\
Ascites (carcinomatosis) & 5 & $(15)$ \\
Pulmonary & 3 & $(9)$ \\
\hline
\end{tabular}

A number of patients progressed synchronously in multiple sites.

reported toxicity has been significant. A phase II ECOG trial evaluating radiation and concurrent protracted venous infusion 5-FU $\left(200 \mathrm{mg} \mathrm{m}^{-2} \mathrm{day}^{-1}\right)$ with weekly gemcitabine (50$100 \mathrm{mg} \mathrm{m}^{-2}$ ) was closed early due to excessive toxicity; three out of seven patients developed severe gastrointestinal toxicities (Talamonti et al, 2000). A phase II Cancer and Leukemia Group $\mathrm{B}$ trial evaluating a similar regimen found the toxicity to be acceptable (Mamon, personal communication). In data from MD Anderson Cancer Center, Wolff et al (2001) observed grade III/IV haematologic toxicity in over $50 \%$ of patients receiving weekly gemcitabine at doses ranging from 350 to $500 \mathrm{mg} \mathrm{m}^{-2}$, with $44 \%$ of the patients requiring hospital admission for severe nausea/ vomiting and dehydration. An expanded retrospective review of patients receiving gemcitabine-based chemoradiation at MD Anderson, as reported by Crane et al (2001), further reflects the difficulties of combining the systemic toxicities of 'full dose' gemcitabine with the local-regional toxicities associated with radiation with the substantial radiation sensitisation of gemcitabine to the upper abdomen. The only trial to date able to achieve
Table 5 Phase III adjuvant chemoradiation trials for adenocarcinoma of the pancreatic head

\begin{tabular}{|c|c|c|c|c|}
\hline Trial & Treatment & $n$ & $\begin{array}{c}\text { \% Stage } \\
\geqslant \text { T3l } \\
\text { \%node (+) }\end{array}$ & $\begin{array}{c}\text { Median } \\
\text { survival } \\
\text { (months) }\end{array}$ \\
\hline GITSG (1987) & $\begin{array}{l}\text { Observation } \\
40 \mathrm{~Gy}+5-\mathrm{FU}^{\mathrm{a}}\end{array}$ & $\begin{array}{l}22 \\
21\end{array}$ & $35 / 28 \%$ & $\begin{array}{l}10.9 \\
20.0\end{array}$ \\
\hline \multirow{2}{*}{$\begin{array}{l}\text { EORTC (Klinkenbijl } \\
\text { et al, 1999) }\end{array}$} & Observation & 60 & 0/47\% & 12.6 \\
\hline & $40 \mathrm{~Gy}+5-F U^{b}$ & 54 & & 17.1 \\
\hline \multirow{2}{*}{$\begin{array}{l}\text { ESPAC (Neoptolemos } \\
\text { et al, 2004) }\end{array}$} & Observation & 69 & & 16.9 \\
\hline & $\begin{array}{l}6 \text { Cycles 5-FU } \\
40 \mathrm{~Gy}+5-\mathrm{FU}^{\mathrm{b}} \\
40 \mathrm{~Gy}+5-\mathrm{FU}^{\mathrm{c}}\end{array}$ & $\begin{array}{l}75 \\
73 \\
72\end{array}$ & $30 / 59 \%$ & $\begin{array}{l}21.6 \\
13.9 \\
19.9\end{array}$ \\
\hline *WFU/Lyon (phase II) & $\begin{array}{l}50 \text { Gy }+ \\
\text { Gemcitabine }^{d}\end{array}$ & 47 & $74 / 70 \%$ & 18.3 \\
\hline
\end{tabular}

aPatients received 5-FU ( 2 doses) during the radiation followed by 2 years of monthly therapy. 'Patients received 5-FU (2 doses) during the radiation only. 'Patients received 5-FU (2 doses) during the radiation followed by six additional months of 5-

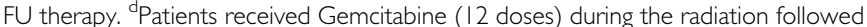
by two additional months of Gemcitabine. 5-FU, 5-fluorouracil.

'full dose' gemcitabine in this setting was reported by the University of Michigan utilising very specific radiation treatment guidelines (McGinn et al, 2001). As reported by McGinn et al, the treated tumour volume was restricted to the gross tumour with a $1.0 \mathrm{~cm}$ margin. No prophylactic nodal irradiation was given and the recommended phase II radiation dose was 36 Gy delivered in $2.4 \mathrm{~Gy}$ fractions.

The clinical experience with radiation and gemcitabine for pancreatic cancer in the adjuvant setting is more limited. Investigators at the University of Michigan found the strategy of fixing the dose of gemcitabine and escalating the 'limited field' radiation to be well tolerated in the adjuvant setting (Allen et al, 2004). In this phase I study of 32 patients with resected pancreatic cancer, gemcitabine at a dose of $1000 \mathrm{mg} \mathrm{m}^{-2}$ was given on days 1 , 8 and 15 of a 28 -day cycle concurrent with the radiation. The maximum tolerated dose of radiation was $39 \mathrm{~Gy}$. While these are phase I data, the median survival was an acceptable 16.5 months. Van Laethem et al, in a feasibility study, found that gemcitabine $\left(300 \mathrm{mg} \mathrm{m}^{-2}\right)$ given weekly with split-course radiation $(40 \mathrm{~Gy} / 20$ fractions over 6 weeks) was tolerable following three cycles of standard dose gemcitabine ( $1000 \mathrm{mg} \mathrm{m}^{-2}$ day 1 and $8 \mathrm{q} 21$ days) (Van Laethem et al, 2003). While limited to 22 patients, the median disease-free survival and overall survival was 6 and 15 months, respectively. In the present trial, $74 \%$ of patients were able to complete the entire chemoradiation portion of the study and receive $\geqslant 3$ of the six planned doses of maintenance chemotherapy. This observation, along with the modest toxicity observed, suggests this regimen is well tolerated in the adjuvant setting.

In an attempt to put these results into perspective, Table 5 provides the results of selected phase III trials evaluating adjuvant chemoradiation strategies. The GITSG study found a benefit with the addition of adjuvant chemoradiation ( $v s$ observation) in a trial of 43 patients (1987). In a randomised study from the EORTC, which was not statistically significant, an almost 5-month survival advantage was observed for patients with pancreatic head cancers randomised to resection and adjuvant 5-FU-based chemoradiation $v s$ observation (Klinkenbijl et al, 1999).

The ESPAC-1 trial attempted to evaluate several adjuvant strategies (Neoptolemos et al, 2004). Following resection, patients 
received either no therapy (observation), split-course radiation with 5-FU given during weeks 1 and 5 (no maintenance chemotherapy), six cycles of adjuvant/maintenance 5-FU chemotherapy, or split-course radiation with 5-FU followed by six cycles of adjuvant/maintenance 5-FU chemotherapy. The data from the ESPAC trial are difficult to interpret as the design of the trial allowed not only for randomisation between chemoradiation and observation but also a separate randomisation according to physician preference, for chemotherapy only, chemoradiation, or observation. Of the 541 patients, 346 (63\%) had undergone either 'background' chemotherapy or chemoradiation prior to randomisation. In evaluating the most clinically relevant treatment arms, median survival for patients randomised to chemotherapy (alone) was 21.6 vs 19.9 months for those patients receiving chemoradiation followed by adjuvant/maintenance chemotherapy, suggesting no benefit with the addition of the radiation. Unfortunately, only $62 \%$ of the chemoradiation patients actually received the prescribed $40 \mathrm{~Gy}$ of radiation and, as stated by the authors, most of the protocol violations $(50 \%)$ on the chemoradiation treatment arms were due to the patient's decision not to receive the assigned treatment.

In our study, the strategy of combining radiation with gemcitabine resulted in an acceptable median survival of over 18 months, despite the vast majority of patients having T3-T4 and/or node positive cancers. As shown in Table 5, the EORTC trial, which only allowed patients with $\mathrm{T} 1-\mathrm{T} 2$ tumours to be enrolled, achieved a median survival of 17 months in patients with pancreatic head cancers. While our trial only included 12 patients who would have been eligible for the EORTC study, the median survival for those patients was 31 months.

The results of our phase II trial may reflect an improved localregional control of disease as well as an improved systemic approach. The $15 \%$ local-regional failure rate observed in the EORTC trial in both the observation and treatment arms is likely accurate for patients with node negative (53\%) and/or T1-T2 periampullary/pancreatic head tumours. In our 46 patient trial, $18 \%$ of the patients with documented recurrences had localregional failures, despite $\mathrm{T} 3-\mathrm{T} 4$ tumours and node positive patients accounting for 73 and $70 \%$ of the patients enrolled, respectively. The overall local recurrence (alone) rate in the ESPAC trial was $35 \%$ and likely reflects the anticipated local failure rate for patients with T3-T4 and/or node positive disease.

It is also possible that the two cycles of standard dose gemcitabine delivered following the chemoradiation may have improved outcomes. In a study of 368 patients with resected pancreatic cancer randomised to observation vs 6 months of adjuvant gemcitabine chemotherapy, Neuhaus et al (2005) observed a 14-month time to tumour recurrence for those patients receiving gemcitabine $v s 7.5$ months for those receiving no further therapy. The majority of patients in this trial had T3-T4 tumours and node positive disease. While survival results were not presented, these data suggest that gemcitabine may provide improved systemic disease control in the adjuvant setting. In the previously referenced CALGB experience utilising this strategy for patients with locally advanced unresectable disease, survival was not improved beyond that observed with 5-FU-based chemoradiation. However, this regimen in the adjuvant setting may be more promising. This perhaps reflects improvements in local-regional disease control with adjuvant gemcitabinebased chemoradiation along with improved systemic therapy (maintenance gemcitabine).

In conclusion, this phase II study confirms the feasibility and acceptable overall toxicity of adjuvant gemcitabine-based chemoradiation followed by maintenance gemcitabine chemotherapy for patients with resected pancreatic cancer. The time to disease recurrence and overall median survival were acceptable while local tumour control appeared improved.

\section{ACKNOWLEDGEMENTS}

We thank Carrie E Blackstock, PhD for her editorial support. The study was supported in-part by Eli Lilly Oncology (US and France) and the Comprehensive Cancer Center of Wake Forest University Community Clinical Oncology Program Research Base Grant 1 U10 CA81851.

\section{REFERENCES}

Allen AM, Zalupski MM, Robertson JM, Eckhauser FE, Simone D, Brown D, Hejna G, Normolle D, Lawrence TS, McGinn CJ (2004) Adjuvant therapy in pancreatic cancer: phase I trial of radiation dose escalation with concurrent full-dose gemcitabine. Int J Radiat Oncol Biol Phys 59: $1461-1467$

Blackstock AW, Bernard SA, Richards F, Eagle KS, Case LD, Poole ME, Savage PD, Tepper JE (1999) Phase I trial of twice-weekly gemcitabine and concurrent radiation in patients with advanced pancreatic cancer. J Clin Oncol 17: 2208-2212

Blackstock AW, Lightfoot H, Case LD, Tepper JE, Mukherji SK, Mitchell BS, Swarts SG, Hess SM (2001) Tumor uptake and elimination of $2^{\prime}, 2^{\prime}$ difluoro- $2^{\prime}$-deoxycytidine (gemcitabine) after deoxycytidine kinase gene transfer: correlation with in vivo tumor response. Clin Cancer Res 7: $3263-3268$

Blackstock AW, Tepper JE, Niedwiecki D, Hollis DR, Mayer RJ, Tempero MA (2004) Cancer and leukemia group B (CALGB) 89805: phase II chemoradiation trial using gemcitabine in patients with locoregional adenocarcinoma of the pancreas. Int J Gastrointest Cancer 34: 107-116

Boven E, Schipper H, Erkelens CA, Hatty SA, Pinedo HM (1993) The influence of the schedule and the dose of gemcitabine on the anti-tumour efficacy in experimental human cancer. Br J Cancer 68: $52-56$

Burris III HA, Moore MJ, Andersen J, Green MR, Rothenberg ML, Modiano MR, Cripps MC, Portenoy RK, Storniolo AM, Tarassoff P, Nelson R, Dorr FA, Stephens CD, Von Hoff DD (1997) Improvements in survival and clinical benefit with gemcitabine as first-line therapy for patients with advanced pancreas cancer: a randomized trial (see comments). J Clin Oncol 15: $2403-2413$
Carmichael J, Fink U, Russell RC, Spittle MF, Harris AL, Spiessi G, Blatter J (1996) Phase II study of gemcitabine in patients with advanced pancreatic cancer. Br J Cancer 73: $101-105$

Casper ES, Green MR, Kelsen DP, Heelan RT, Brown TD, Flombaum CD, Trochanowski B, Tarassoff PG (1994) Phase II trial of gemcitabine (2,2'-difluorodeoxycytidine) in patients with adenocarcinoma of the pancreas. Invest New Drugs 12: $29-34$

Crane CH, Janjan NA, Evans DB, Wolff RA, Ballo MT, Milas L, Mason K, Charnsangavej C, Pisters PW, Lee JE, Lenzi R, Vauthey JN, Wong A, Phan T, Nguyen Q, Abbruzzese JL (2001) Toxicity and efficacy of concurrent gemcitabine and radiotherapy for locally advanced pancreatic cancer. Int J Pancreatol 29: 9-18

Eisbruch A, Shewach DS, Bradford CR, Littles JF, Teknos TN, Chepeha DB, Marentette LJ, Terrell JE, Hogikyan ND, Dawson LA, Urba S, Wolf GT, Lawrence TS (2001) Radiation concurrent with gemcitabine for locally advanced head and neck cancer: a phase I trial and intracellular drug incorporation study. J Clin Oncol 19: $792-799$

Fields MT, Eisbruch A, Normolle D, Orfali A, Davis MA, Pu AT, Lawrence TS (2000) Radiosensitization produced in vivo by once- $v$ s twice-weekly 2'2'-difluoro-2'-deoxycytidine (gemcitabine). Int J Radiat Oncol Biol Phys 47: $785-791$

Gandhi V, Plunkett W (1990) Modulatory activity of $2^{\prime}, 2^{\prime}$-difluorodeoxycytidine on the phosphorylation and cytotoxicity of arabinosyl nucleosides. Cancer Res 50: 3675-3680

Gastrointestinal Tumor Study Group (1987) Further evidence of effective adjuvant combined radiation and chemotherapy following curative resection of pancreatic cancer. Cancer 59: 2006-2010 
Grunewald R, Abbruzzese JL, Tarassoff P, Plunkett W (1991) Saturation of $2^{\prime}, 2^{\prime}$-difluorodeoxycytidine $5^{\prime}$-triphosphate accumulation by mononuclear cells during a phase I trial of gemcitabine. Cancer Chemother Pharmacol 27: 258-262

Joensuu TK, Kiviluoto T, Karkkainen P, Vento P, Kivisaari L, Tenhunen M, Westberg R, Elomaa I (2004) Phase I-II trial of twice-weekly gemcitabine and concomitant irradiation in patients undergoing pancreaticoduodenectomy with extended lymphadenectomy for locally advanced pancreatic cancer. Int J Radiat Oncol Biol Phys 60: 444-452

Joschko MA, Webster LK, Groves J, Yuen K, Palatsides M, Ball DL, Millward MJ (1997) Enhancement of radiation-induced regrowth delay by gemcitabine in a human tumor xenograft model. Radiat Oncol Invest 5: $62-71$

Klinkenbijl JH, Jeekel J, Sahmoud T, van Pel R, Couvreur ML, Veenhof CH, Arnaud JP, Gonzalez DG, de Wit LT, Hennipman A, Wils J (1999) Adjuvant radiotherapy and 5-fluorouracil after curative resection of cancer of the pancreas and periampullary region. Phase III trial of the EORTC GITCCG. Ann Surg 230: 776-784

Lawrence TS, Chang EY, Hahn TM, Hertel LW, Shewach DS (1996) Radiosensitization of pancreatic cancer cells by $2^{\prime}, 2^{\prime}$-difluoro-2'-deoxycytidine. Int I Radiat Oncol Biol Phys 34: 867-872

Lawrence TS, Chang EY, Hahn TM, Shewach DS (1997) Delayed radiosensitization of human colon carcinoma cells after a brief exposure to 2',2'-difluoro-2'-deoxycytidine (Gemcitabine). Clin Cancer Res 3: $777-782$

Lawrence TS, Eisbruch A, McGinn CJ, Fields MT, Shewach DS (1999) Radiosensitization by gemcitabine. Oncology (Huntington) 13: 55-60

Martenson JA, Vigliotti AP, Pitot HC, Geeraerts LH, Sargent DJ, Haddock MG, Ghosh C, Keppen MD, Fitch TR, Goldberg RM (2003) A phase I study of radiation therapy and twice-weekly gemcitabine and cisplatin in patients with locally advanced pancreatic cancer. Int J Radiat Oncol Biol Phys 1(55): $1305-1310$

Mason KA, Milas L, Hunter NR, Elshaikh M, Buchmiller L, Kishi K, Hittelman K, Ang KK (1999) Maximizing therapeutic gain with gemcitabine and fractionated radiation. Int J Radiat Oncol Biol Phys 44: $1125-1135$

McGinn CJ, Zalupski MM, Shureiqi I, Robertson JM, Eckhauser FE, Smith DC, Brown D, Hejna G, Strawderman M, Normolle D, Lawrence TS (2001) Phase I trial of radiation dose escalation with concurrent weekly full-dose gemcitabine in patients with advanced pancreatic cancer. J Clin Oncol 19: $4202-4208$
Neoptolemos JP, Stocken DD, Friess H, Bassi C, Dunn JA, Hickey H, Berger H, Fernandez-Cruz L, Dervenis C, Lacaine F, Falconi M, Pederzoli P, Pap A, Spooner D, Kerr DJ, Buchler MW (2004) A randomized trial of chemoradiotherapy and chemotherapy after resection of pancreatic cancer. N Engl J Med 350: 1200 - 1210

Neuhaus P, Oettle H, Post S, Gellert K, Ridwelski K, Schramm H, Zülke C, Fahlke J, Langrehr H, Riess H (2005) A randomized, prospective, multicenter, phase III trial of adjuvant chemotherapy with gemcitabine $v s$ observation in patients with resected pancreatic cancer. ASCO Annual Meeting Proceedings 23, 16S, \#4013

Pipas JM, Mitchell SE, Barth RJJ, Vera-Gimon R, Rathmann J, Meyer LP, Wagman RS, Lewis LD, McDonnell C, Colacchio TA, Perez RP (2001) Phase I study of twice-weekly gemcitabine and concomitant externalbeam radiotherapy in patients with adenocarcinoma of the pancreas. Int $J$ Radiat Oncol Biol Phys 50: 1317-1322

Shewach DS, Hahn TM, Chang E, Hertel LW, Lawrence TS (1994) Metabolism of $2^{\prime}, 2^{\prime}$-difluoro- $2^{\prime}$-deoxycytidine and radiation sensitization of human colon carcinoma cells. Cancer Res 54: 3218-3223

Shewach DS, Lawrence TS (1995) Radiosensitization of human tumor cells by gemcitabine in vitro. Semin Oncol 22: 68-71

Shewach DS, Lawrence TS (1996) Radiosensitization of human solid tumor cell lines with gemcitabine. Semin Oncol 23: 65-71

Talamonti MS, Catalano PJ, Vaughn DJ, Whittington R, Beauchamp RD, Berlin J, Benson III AB (2000) Eastern Cooperative Oncology Group Phase I trial of protracted venous infusion fluorouracil plus weekly gemcitabine with concurrent radiation therapy in patients with locally advanced pancreas cancer: a regimen with unexpected early toxicity. J Clin Oncol 18: $3384-3389$

Van Laethem J-L, Demols A, Gay F, Closon MT, Colette M, Polus M, Houbiers G, Gastelblum P, Gelin M, Houtte PV, Closset J (2003) Postoperative adjuvant gemcitabine and concurrent radiation after curative resection of pancreatic head carcinoma: a phase II study. Int J Radiat Oncol Biol Phys 56: 974-980

Wolff RA, Evans DB, Gravel DM, Lenzi R, Pisters PW, Lee JE, Janjan NA, Charnsangavej C, Abbruzzese JL (2001) Phase I trial of gemcitabine combined with radiation for the treatment of locally advanced pancreatic adenocarcinoma. Clin Cancer Res 7: 2246-2253

Yavuz AA, Aydin F, Yavuz MN, Ilis E, Ozdemir F (2001) Radiation therapy and concurrent fixed dose amifostine with escalating doses of twiceweekly gemcitabine in advanced pancreatic cancer. Int J Radiat Oncol Biol Phys 51: $974-981$ 